Rev. Bras. Saúde Prod. Anim., Salvador, v.16, n.4, p.925-934 out../dez.., 2015 http://www.rbspa.ufba.br

\title{
Variações diurna e sazonal da defensividade das abelhas africanizadas (Apis mellifera L.)
}

\author{
Diurnal and seasonal changes of defensive behavior of Africanized bees ("Apis \\ mellifera" L.)
}

\author{
SILVEIRA, Daniel Casimiro da ${ }^{1}$; MARACAJÁ, Patrício Borges ${ }^{1}$; SILVA, Rosilene \\ Agra da ${ }^{1}$; SOUSA, Raimundo Maciel $^{2}$; SOTO-BLANCO, Benito ${ }^{3 *}$
}

\author{
${ }^{1}$ Universidade Federal de Campina Grande, Centro de Ciências e Tecnologia Agroalimentar, Unidade \\ Acadêmica de Agronomia, Pombal, Paraíba, Brasil. \\ ${ }^{2}$ Instituto Federal do Ceará, Fortaleza, Ceará, Brasil. \\ ${ }^{3}$ Universidade Federal de Minas Gerais, Escola de Veterinária, Departamento de Clínica e Cirurgia \\ Veterinárias, Belo Horizonte, Minas Gerais, Brasil. \\ *Endereço para correspondência: benito.blanco@pq.cnpq.br
}

RESUMO

A defensividade das abelhas Apis mellifera L. é uma forma de proteção contra os predadores e evitar o roubo na colmeia. Este trabalho teve o objetivo de avaliar a variação diurna e sazonal na defensividade das abelhas Africanizadas, por meio de testes de comportamento defensivo. A pesquisa foi realizada em três apiários no sertão do estado da Paraíba. Cada apiário possuia 30 enxames, alojados em colmeias padrão Langstroth. Destas, foram selecionadas aleatoriamente 10 colônias e identificadas de 01 à 10 , com população adulta e área de cria semelhante. Os testes de defensividade foram realizados em cada colmeia, uma por vez, escolhida em três repetições, nos horários de 07:00 às 10:00 horas, de 12:00 às 14:00 horas e das 15:00 às 17:00 horas, e em duas etapas, em um mês da estação chuvosa (Abril) e outro mês da estação seca (Agosto), sendo realizado apenas uma vez por mês, devido a grande perda de abelhas por teste. A partir dos resultados obtidos observamos que o horário influenciou positivamente na defensividade das abelhas analisadas, sendo das $15: 00 \mathrm{~h}$ às $17: 00 \mathrm{~h}$ aquele de maior agressividade nos dois períodos do ano. Na estação da seca as abelhas se apresentaram menos defensivas do que na estação das chuvas. A análise dos dados caracterizam as abelhas como altamente defensivas, sendo maior ao final da tarde e na época das chuvas.

Palavras-chave: apicultura, defesa, período, tempo

\section{SUMMARY}

The defensive behavior of Apis mellifera L. is a form of protection from predators and prevent theft in the hive. This work aimed to evaluate the diurnal and seasonal variation in defensiveness of Africanized bees through defensive behavior tests. The survey was conducted in three apiaries in the Paraiba state, Brazil. Every apiary had 30 colonies, housed in standard Langstroth hives. From them, 10 colonies were randomly selected and identified from 01 to 10 , with similar adult population and raising area. The defensive behavior tests were performed on each hive, one at a time, chosen in three repetitions, the times of 07:00 to 10:00, from $12: 00$ to $14: 00$ and $15: 00$ to $17: 00$ and in two stages, in a month of the rainy season (April) and another month of the dry season (August), being held only once a month, due to the large loss test by bees. The obtained results showed that the time positively influenced the defensiveness of the analyzed bees, being from 15: $00 \mathrm{~h}$ to $17: 00 \mathrm{~h}$ the time of most aggressiveness in both periods of the year. In the dry season the bees showed less defensive than in the rainy season. The analysis of obtained data characterized the bees as highly defensive, with most evident defensiveness at the evening and the rainy season.

Keywords: beekeeping, defense, period, time 


\section{INTRODUÇÃOO}

A apicultura vem ganhando espaço no Brasil como uma atividade rentável, pois apresenta retorno rápido do capital investido. Além disso, as condições climáticas são bastante favoráveis ao desenvolvimento das abelhas Apis mellifera L. (MENDES et al., 2009).

O comportamento defensivo executado pelas abelhas melíferas representa uma defesa da colônia contra potenciais saqueadores, uma vez que seus ninhos contêm estoques de mel e pólen, além da abundância de cria que atrai diversos predadores (PAPACHRISTOFOROU et al., 2011; KASPEREK et al., 2012). O elaborado sistema de defesa das abelhas tem evoluído juntamente com a capacidade de atração das abelhas por recursos alimentares, em particular ao comportamento de forrageamento, e para se defender, defender o alimento estocado e proteger a colônia de predadores, a fim de minimizar perdas e despesas (KASTBERGER et al., 2008). As estratégias de defensividade das abelhas são como o comportamento dos soldados com as mais diversas funções. As abelhas guardas estão no alvado da colônia com o principal objetivo de vigiar, identificar e remover intrusos (BREED et al., 2004; STABENTHEINER et al., 2002; STABENTHEINER et al., 2007).

As diferenças no comportamento defensivo, como em outras características biológicas, estão relacionadas a fatores genéticos e ambientais, como temperatura, umidade e pressão atmosférica (PAPACHRISTOFOROU et al., 2011; KASPEREK et al., 2012), bem como a disponibilidade de alimento para a colônia (NASCIMENTO et al., 2005). As linhagens originalmente criadas no Brasil eram principalmente da linhagem italiana (Apis mellifera ligustica), mas a fuga de colônias de abelhas africanas (Apis mellifera scutellata) resultou na progressiva hibridização dos enxames brasileiros. Como consequência, o aumento da defensividade e da propensão à enxameação foram características da africanização que, na época, causaram vários transtornos à população e muitos apicultores comerciais saíram do ramo ou reduziram drasticamente seus apiários (KERR, 1967; GONÇALVES, 1974; KAPLAN, 2007).

Diante da necessidade de reduzir os possíveis acidentes ocorridos com $\mathrm{o}$ ataque das abelhas e facilitar o manejo das colmeias, objetivou-se avaliar a defensividade das abelhas africanizadas no sertão paraibano, através da investigação da influência do horário e do período sazonal sobre o comportamento defensivo dessas abelhas nos períodos de chuva e seca.

\section{MATERIAL E MÉTODOS}

A pesquisa foi realizada em três apiários nos municípios de Condado, Pombal e Sousa no alto sertão do estado da Paraíba. Cada apiário selecionado possui 30 enxames de abelhas Apis mellifera L. africanizadas, alojadas em colmeias padrão Langstroth, instalado em local de fácil acesso e distante de pessoas e animais. Destas, foram selecionadas aleatoriamente 10 colônias, distantes entre si por 10 metros, em mata pouco densa, identificadas de 01 à 10, com população adulta e área de cria semelhante.

Os testes de defensividade foram realizados em cada colmeia, uma por vez, escolhida em 3 repetições, nos horários de 07:00 às 10:00 horas, de $12: 00$ às 14:00 horas e das 15:00 às 17:00 horas, e em duas etapas, em um mês da estação chuvosa (Abril) e outro 
mês da estação seca (Agosto), sendo realizado apenas uma vez por mês, devido a grande perda de abelhas por teste

A agressividade foi medida pelo método de Stort (1974), com algumas adaptações, onde o tempo para $\mathrm{o}$ enfurecimento (TE) das abelhas foi medido em segundos, desde a presença do manipulador em frente à colmeia até a movimentação intensa das abelhas no alvado. $\mathrm{O}$ tempo para ocorrer à primeira ferroada (TFC) foi medido em segundos, logo após ter determinado o tempo de enfurecimento até se observar a primeira ferroada em uma camurça (inimigo artificial) de $5 \times 5 \mathrm{~cm}$ de tamanho com coloração cinza claro, presa por um cordão branco em um recipiente circular de $32 \mathrm{~cm}$ de diâmetro e $12 \mathrm{~cm}$ de altura e determinado também o número de ferrões deixados na camurça (NFC). O número de abelhas que atacaram (NAPR) a camurça foi determinado através do fechamento do recipiente circular após 1 minuto da primeira ferroada. Decorrido o tempo, a camurça e o recipiente foram trocadas a cada teste para evitar a influência de feromônios, foram colocadas dentro de outro recipiente, levadas para o laboratório, colocadas na geladeira para matar as abelhas e fazer contagem dos ferrões que ficaram presos na camurça.

A distância que as abelhas perseguiram (DP) o manipulador foi medida logo após ser fechado o recipiente no teste anterior, onde ao ser fechado o manipulador saia andando em linha reta pelo local do estudo e contando os passos até não mais ser perseguido pelas abelhas. A distância de perseguição das abelhas foi medida em metros. Já o tempo para a calmaria (TCC) das abelhas na colônia foi medido em minutos desde a saída do manipulador da frente da colmeia até observarmos que abelhas não voavam mais sobre o ninho, se concentravam no alvado e entravam na colmeia.

Devido à defensividade das abelhas, aplicamos fumaça nas colmeias que não foram testadas, a fim de que as abelhas que perseguissem o manipulador fosse apenas as das colmeias avaliadas. Para medir o tempo gasto para que ocorra o enfurecimento das abelhas, a primeira ferroada na camurça e o tempo para as abelhas acalmarem-se na colmeia usamos um cronômetro digital. Durante os testes mais de um pesquisador foi usado para a coleta dos tempos.

Os dados foram expressos em média das três repetições realizadas seguida do respectivo desvio padrão e avaliados pelos programas estatísticos SAS (SAS, 2002) versão 9.0 e SigmaPlot for Windows (2014) versão 12.0. Após análise da normalidade pelo teste de Shapiro-Wilk, e homogeneidade de variância por Bartlett, os parâmetros biológicos das abelhas foram avaliados por análise de variância para medidas repetidas, seguida do teste de Tukey. Sempre que necessário utilizou-se da transformação logarítmica para garantir os pressupostos paramétricos. Valores de $\mathrm{P}<0,05$ foram considerados significativos. Para agrupar as colmeias estudadas pela característica de baixa defensividade, analisaram-se os dados pelo método de Ward, dando origem a "clusters" que são representados num dendrograma, que é a forma gráfica mais usada para representar o resultado final dos diversos agrupamentos, relacionando as variáveis com as distâncias euclidianas. O método de Ward, também chamado de "Mínima Variância", é utilizado nas análises de dados multivariados (WARD JUNIOR, 1967). Nesse método a formação dos grupos se dá pela maximização da homogeneidade dentro dos grupos. A soma de quadrados dentro dos grupos é usada como medida 
Rev. Bras. Saúde Prod. Anim., Salvador, v.16, n.4, p.925-934 out../dez.., 2015 http://www.rbspa.ufba.br ISSN 15199940

de homogeneidade. Isto é, o método de Ward tenta minimizar a soma de quadrados dentro do grupo. Os grupos formados em cada passo são resultantes de grupo solução com a menor soma de quadrados (SHARMA, 1995).

\section{RESULTADOS E DISCUSSÃO}

$\mathrm{Na}$ Tabela 1 estão apresentadas as médias das variáveis biológicas entre o período de chuvas e de seca nos três apiários nos diferentes horários nas colmeias testadas. Com relação ao tempo para o enfurecimento das abelhas observamos que no período de chuvas nos horários compreendidos entre 7:00 às 10:00 horas e das 12:00 às 14:00 horas do dia com valores de, respectivamente, 4,03 e 3,46 s, sendo estes estatisticamente diferentes dos observados no período de $15: 00$ às $17: 00$ horas $(2,56 \mathrm{~s})$. O tempo médio obtido para esta variável se mostra inferior ao obtido por Stort (1974), 9,04 segundos, quando avaliava a defensividade de abelhas $A$. mellifera no Brasil.

Tabela 1. Médias das variáveis estudadas entre o período de chuvas e de seca nos três apiários nos diferentes horários.

\begin{tabular}{lcccc}
\hline \multirow{2}{*}{ Variáveis } & Período & \multicolumn{3}{c}{ Horários (h) } \\
\cline { 3 - 5 } & & $7: 00-10: 00$ & $12: 00-14: 00$ & $15: 00-17: 00$ \\
\hline \multirow{2}{*}{ TE (segundos) } & Chuvas & $4,03 \pm 1,47^{\mathrm{B}, \mathrm{a}}$ & $3,46 \pm 1,25^{\mathrm{B}, \mathrm{a}}$ & $2,56 \pm 1,22^{\mathrm{A}, \mathrm{b}}$ \\
& Seca & $4,56 \pm 1,16^{\mathrm{A}, \mathrm{a}}$ & $3,93 \pm 1,22^{\mathrm{A}, \mathrm{b}}$ & $2,76 \pm 1,07^{\mathrm{A}, \mathrm{b}}$ \\
\multirow{2}{*}{ TFC } & Chuvas & $6,03 \pm 2,12^{\mathrm{B}, \mathrm{a}}$ & $5,00 \pm 1,64^{\mathrm{B}, \mathrm{b}}$ & $3,86 \pm 1,81^{\mathrm{B}, \mathrm{c}}$ \\
& Seca & $6,63 \pm 1,84^{\mathrm{A}, \mathrm{a}}$ & $5,70 \pm 1,66^{\mathrm{A}, \mathrm{b}}$ & $4,50 \pm 1,63^{\mathrm{A}, \mathrm{c}}$ \\
NFC & Chuvas & $40,20 \pm 23,93^{\mathrm{A}, \mathrm{c}}$ & $50,91 \pm 25,11^{\mathrm{A}, \mathrm{b}}$ & $62,13 \pm 24,62^{\mathrm{A}, \mathrm{a}}$ \\
& Seca & $25,42 \pm 16,81^{\mathrm{B}, \mathrm{c}}$ & $31,54 \pm 19,86^{\mathrm{B}, \mathrm{b}}$ & $42,08 \pm 23,01^{\mathrm{B,a}}$ \\
NAPR & Chuvas & $40,92 \pm 19,64^{\mathrm{A}, \mathrm{c}}$ & $52,02 \pm 23,23^{\mathrm{A}, \mathrm{b}}$ & $66,16 \pm 24,72^{\mathrm{A}, \mathrm{a}}$ \\
& Seca & $26,80 \pm 15,85^{\mathrm{B}, \mathrm{c}}$ & $32,34 \pm 18,66^{\mathrm{B}, \mathrm{b}}$ & $43,11 \pm 22,19^{\mathrm{B}, \mathrm{a}}$ \\
DP (metros) & Chuvas & $309,61 \pm 130,77^{\mathrm{A}, \mathrm{c}}$ & $325,83 \pm 140,42^{\mathrm{A}, \mathrm{b}}$ & $356,14 \pm 134,05^{\mathrm{A}, \mathrm{a}}$ \\
& Seca & $259,70 \pm 84,48^{\mathrm{B}, \mathrm{b}}$ & $270,35 \pm 87,53^{\mathrm{B}, \mathrm{b}}$ & $309,52 \pm 94,22^{\mathrm{B}, \mathrm{a}}$ \\
\multirow{2}{*}{ TCC (minutos) } & Chuvas & $32,94 \pm 8,14^{\mathrm{A}, \mathrm{b}}$ & $37,91 \pm 9,23^{\mathrm{A}, \mathrm{a}}$ & $42,12 \pm 9,50^{\mathrm{A}, \mathrm{a}}$ \\
& Seca & $32,31 \pm 7,87^{\mathrm{A}, \mathrm{c}}$ & $34,42 \pm 8,76^{\mathrm{B}, \mathrm{b}}$ & $40,85 \pm 9,03^{\mathrm{A}, \mathrm{a}}$ \\
\hline
\end{tabular}

Resultados das análises com média de três repetições ( \pm desvio padrão). Médias seguidas pela mesma letra (maiúscula na coluna e minúscula na linha) não diferem pelo teste de Tukey $(\mathrm{P}<0,05)$.

Tanto no período chuvoso como no de seca houve diferença significativa nos horários compreendidos entre 7:00 às 10:00 horas e das 12:00 às 14:00 horas, nos dando um maior tempo de enfurecimento no primeiro horário $(4,56$ s) e no período da seca, indicando que este horário e este período sazonal seja de menor defensividade, talvez porque no início do dia as abelhas saiam para coletar alimento e com isto as colmeias fiquem menos populosas e no período da seca por ser uma estação de escassez de alimentos, fazendo com que as 
abelhas passem mais tempo no campo à procura de alimento e deixando suas colônias mais vulneráveis. Outra hipótese seria pela diminuição da população no período seco, bem como pela redução do estoque de alimento e cria no período de escassez de alimento, pois em todos os horários avaliados no período seco demorou mais para $\mathrm{o}$ enfurecimento, com exceção do último período que permitiu a defesa da colmeia com o maior numero de campeiras na caixa.

No período de seca, observamos o menor tempo de enfurecimento no período de 12:00 às 14:00 horas e de $15: 00$ às 17:00 horas do dia (3,93 e 2,76 s), sendo o período maior agressividade das abelhas. Quando comparado o comportamento das abelhas entre as estações de chuvas e seca, observamos que o tempo de enfurecimento das abelhas não diferiu estatisticamente no horário de 15:00 às 17:00 horas, mostrando que em ambos os períodos as colmeias estão mais populosas, talvez por ser nesse horário a volta das abelhas campeiras para a colmeia, dando uma maior proteção à sua colmeia.

Collins et al. (1988) estudaram a agressividade das abelhas africanizadas e italianas, A. mellifera ligustica, resultantes de acasalamentos ao ar livre, e demonstraram que a abelha africanizada é mais agressiva que a abelha italiana porque aquela responde à presença de feromônio de alarme mais rápido, ou seja, em média 3,6 $\pm 0,7 \mathrm{~s}$. Já o tempo médio da resposta da abelha italiana é de $8,8 \pm 0,7 \mathrm{~s}$. O número de abelhas na entrada das colmeias após noventa segundos da liberação do feromônio de alarme foi de 137,2 $\pm 22,8$ para abelhas africanizadas e de 47,4 \pm 22 para abelhas italianas.

A partir destas análises observamos o comportamento das abelhas no período de seca, onde elas saem em busca de alimento e demoram mais para encontrar, deixando a colônia menos populosa no começo do dia e consequentemente menos agressiva, mas ao retornarem do campo, principalmente no entardecer, povoam novamente a colmeia em maior número de abelhas, assim tornando a colmeia mais defensiva por motivo de mais abelhas defenderem sua casa e seu alimento. Esta observação poderá ser útil ao apicultor para saber que no fim do dia e à noite, as abelhas estarão mais defensivas que pela manhã e escolher o melhor horário de manipulação das colmeias.

Logo após ter determinado o tempo de enfurecimento das abelhas é contado o tempo para que ocorra a primeira ferroada, medido em segundos, em um inimigo artificial (camurça) e foi observado que este tempo foi menor no período das 15:00 às 17:00 horas do dia tanto no período das chuvas $(3,86 \mathrm{~s})$ como na seca $(4,50 \mathrm{~s})$, concluindo que as abelhas neste período observado se apresentam mais defensivas e difíceis de manipular. Todos os horários analisados entre os períodos de chuvas e seca, os valores se apresentaram diferentes estatisticamente.

De acordo com Medeiros et al (2013), o período de $15 \mathrm{~h} 00 \mathrm{~min}$ ás $17 \mathrm{~h} 00 \mathrm{~min}$ as abelhas atacaram mais rapidamente com um tempo médio de 2,70 segundos, onde nesse horário a grande maioria das abelhas está voltando do campo.

Nascimento et al. (2005), estudando a agressividade de $A$. mellifera em três intervalos de tempo, verificaram que, no período de 07:00 às 09:00 horas, o tempo médio para ocorrer a primeira ferroada de foi 9,33 segundos; no período de 10:00 às 12:00 horas, o tempo médio para ocorrer a primeira ferroada foi de 3,81 segundos; e no período de 13:00 às 17:00 horas, o tempo médio para ocorrer a primeira ferroada foi de 3,7 segundos. 
A correlação entre o comportamento defensivo e a produtividade de mel não mostrou uma correlação positiva $(\rho=0,490)$ entre si, no nível de $5 \%$ de significância, o que mostra que essas duas variáveis não estão suficientemente interligadas. Dessa forma, mostra-se viável a seleção de colmeias com baixa defensividade e com alta produtividade de mel, de maneira a viabilizar o manejo apropriado e contínuo, além de assegurar a proteção das pessoas que desenvolvem essa atividade (DE SOUZA et al., 2012).

O número de ferrões deixados na camurça também foi maior no período de 15:00 às 17:00 horas do dia, sendo superior no período de chuvas (média de 62,1 ferroadas) quando comparado com o período de seca (média de 42,0 ferroadas), apresentando resultado semelhante a Nascimento et al. (2005) que indicaram ser no primeiro período de 7:00 às 9:00 horas, ocorrer um menor número de picadas, contudo, verifica que o número de ferrões foi maior entre 15:00 e 17:00 horas. Isso, provavelmente, se deve ao retorno das abelhas campeiras para a colmeia, pois sabe-se que estas, tendo maior idade são mais aptas a ferroar, o que incrementa a defesa da colmeia.

O número de abelhas presas no recipiente que após 1 minuto da ocorrência da primeira ferroada foi também maior no período da tarde, de 15:00 às 17:00 horas do dia, diferindo estatisticamente entre os demais tratamentos utilizados.

Estudos realizados para observar a variação do comportamento defensivo das abelhas em função das horas de revisões revelam que a reação das abelhas à manipulação parece não ser uniforme, mostrando-se menos intensa no início, com um aumento dessa agressividade no meio e no fim do dia (SILVA et al., 2012).
Quando determinada a distância que as abelhas perseguem o manipulador contando em metros até não mais ser perseguido, esta foi maior no período observado de 15:00 às 17:00 horas do dia no período de chuvas e seca, sendo maior na estação chuvosa, com 356,13 metros. $\mathrm{Na}$ seca, não houve diferença estatística entre os horários compreendidos entre 7:00 e 14:00 horas do dia, sendo a menor distância percorrida no horário das 7:00 às 10:00 horas do dia com 259,73 metros.

Nascimento et al. (2008) observaram que das 7:00 às 9:00 horas a perseguição foi maior chegando a alcançar 293,28 metros, diferente do que foi encontrado neste trabalho para o período das 15:00 as 17:00 horas, de maior perseguição, provavelmente devido ao tempo de exposição do inimigo artificial que foi de 1 minuto, ao contrário do tempo usado por aqueles autores (40 segundos), o que pode estar condicionado ao fato de haver um maior tempo para que mais operárias sejam instigadas pelo feromônio de alarme, e possam sair em defesa de sua colmeia, ou até mesmo pelo percurso e densidade da vegetação por onde $\mathrm{o}$ pesquisador saiu em fuga.

Após as análises de defensividade das abelhas foi determinado também $o$ tempo, em minutos, para que as abelhas se acalmassem na colmeia e foi observado que no período das chuvas. Elas demoram mais a se acalmar no período compreendido das 12:00 às 17:00 horas do dia, não diferindo estatisticamente entre estes horários observados. O menor tempo observado foi no período da seca entre os horários de 7:00 às 10:00 horas da manhã, que levou 32,26 minutos para a calmaria das abelhas nas colmeias.

Queiroga et al (2014) observou que o tempo que as abelhas levam para se acalmarem na colmeia também determina o grau de defensividade, pois 
quanto maior o tempo, mais defensivas elas são, pois o tempo que as abelhas levam para se acalmarem na sua respectiva colmeia, onde o maior tempo foi o de 67 minutos, diferenciando de forma significativa das colmeias não alimentadas no parâmetro tempo para calmaria, onde houve uma maior média de 23 minutos.

De acordo com De Souza et al (2012), as colônias de origem europeia provavelmente encaixam-se na categoria de "mansas", uma vez que apresentam baixo comportamento defensivo. Entretanto, estudos mais aprofundados a esse respeito, com colônias geneticamente puras dessas linhagens, são necessários para comprovação dessa hipótese.

As características genéticas podem influenciar, e muito, no comportamento defensivo das abelhas. Dentre os fatores que influenciam a defensividade $o$ principal é o hereditário. A raça é um fator genético de grande relevância, exercendo forte efeito sobre este comportamento. Estudando a agressividade de abelhas africanizadas e abelhas italianas sobre as mesmas condições, Stort (1974) pôde comprovar que abelhas africanizadas são mais agressivas que abelhas italianas. Quanto ao período sazonal sabemos que na estação da seca têm-se pouco alimento para as abelhas, tornando-as mais fracas e, possivelmente menos defensivas.

$\mathrm{Na}$ Figura 1, estão apresentados os "clusters" produzidos a partir da análise de dados multivariados representados por um dendrograma das colmeias estudadas das três localidades com características de baixa defensivividade. A análise de clusters foi aplicada para os dados multivariados, empregando-se a distância euclidiana para calcular as similaridades das amostras e foi utilizado um procedimento de agrupamento hierárquico para a característica de baixa defensividade e estabelecer os clusters. Os resultados obtidos podem ser observados no dendrograma da Figura 1, onde ocorrem três agrupamentos distintos (A, B. e C) com similaridade de aproximadamente $5 \%$.

De cima para baixo, o agrupamento A formado com similaridade de $2 \%$ constitui-se das colmeias 5, 8, 3, 4, 6 e 1 do município de Pombal e 8 do município de Sousa-PB, indicando uma semelhança mais uniforme no baixo comportamento defensivo dos enxames de Pombal-PB e sugerindo a descendência dos cruzamentos dessas colmeias.

$\mathrm{O}$ agrupamento $\mathrm{B}$, com similaridade de $4 \%$, contém as colmeias $7,10,2,9$ e 4 da região de Sousa-PB e colmeias 9 e 7 da região de Pombal-PB, apresentando maior similaridade nas colmeias de Sousa, também indicando que o cruzamento entre abelhas de um mesmo local transmitem suas características de comportamento aos seus descendentes, mantendo as características da raças. Essa análise nos orienta a utilizar essas colmeias para um trabalho que exija a característica de abelhas mansas.

Por fim, o agrupamento C, com similaridade de $3 \%$, é formado pelas 10 colmeias de Condado-PB, colmeias 5, 6, 3 e 1 da região de Sousa-PB e colmeias 1 e 2 da cidade de Pombal-PB. Esse agrupamento apresenta um número maior de colmeias, em destaque para as de Condado, que todas apresentam o mesmo comportamento, confirmando a permanência da característica dos enxames produzidos naquela região, sendo indicado o melhor local, dentre os estudados, para estudos que necessitem de enxames com um comportamento defensivo baixo. 
Rev. Bras. Saúde Prod. Anim., Salvador, v.16, n.4, p.925-934 out../dez.., 2015 http://www.rbspa.ufba.br

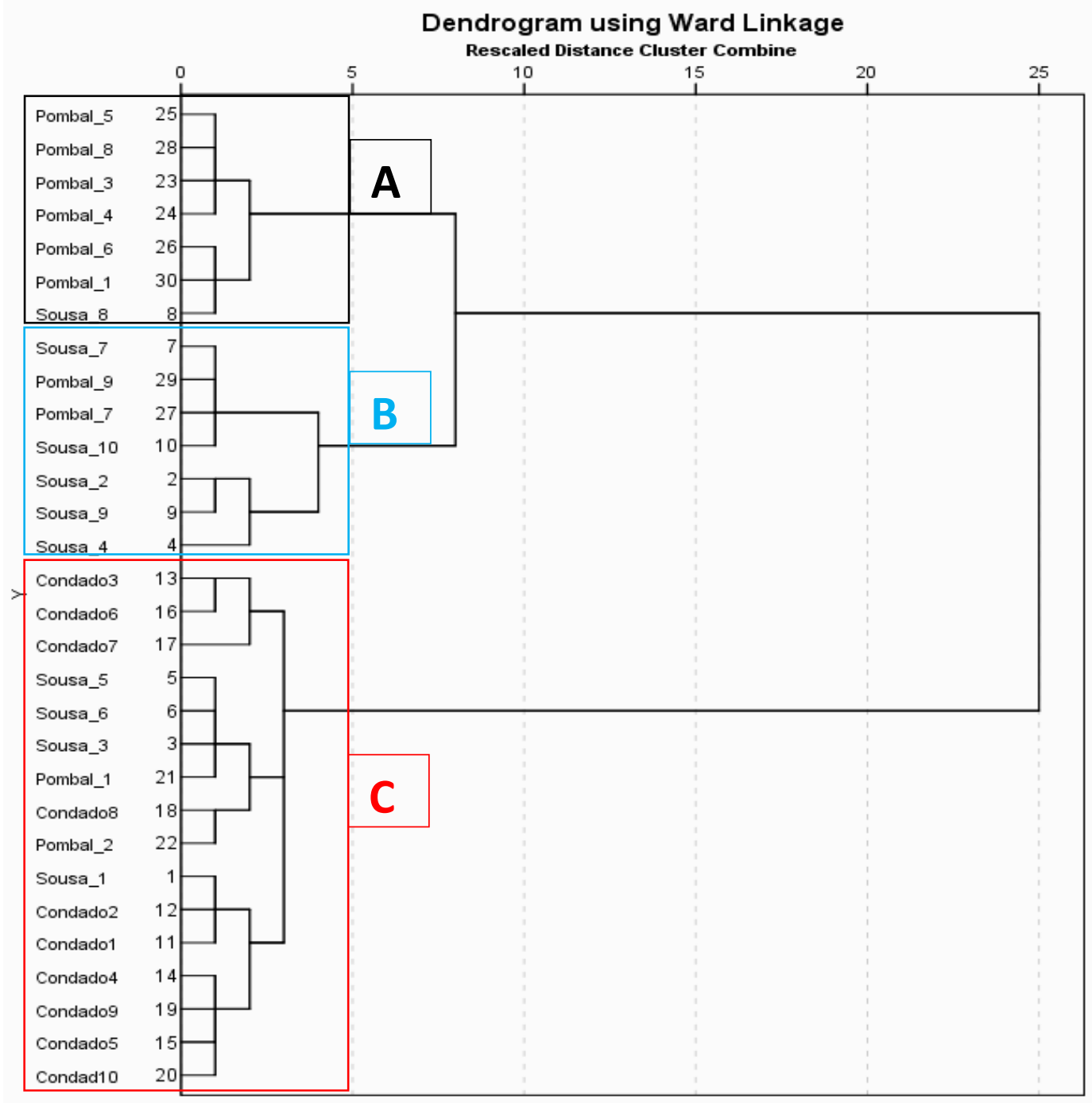

Figura 1. Dendrograma para todas as variáveis e localidades

Dentre todas as colmeias analisadas observamos que elas possuem características em comum, independente do local de origem, podendo agrupa-las de modo a qualificá-las como defensivas ou não através de seu comportamento e assim obter dados preliminares para futura triagem para seleção genética, na produção de abelhas rainha mansas e produtivas visando melhorar e facilitar o manejo nos apiários.

Brandeburgo \& Gonçalves (1990), em similar pesquisa a respeito do comportamento defensivo, no qual analisaram colônias capturadas na natureza, encontraram semelhante variabilidade na expressão desse comportamento. Segundo esses autores, essa diversidade é decorrente das diferenças genéticas entre as colônias.

Assim, a partir dos resultados obtidos podemos concluir que $o$ horário influenciou positivamente na defensividade das abelhas analisadas, sendo o horário da tarde (15:00 às 17:00 horas) como o de maior agressividade nos dois períodos do ano observado. Quanto ao período, na estação da seca as abelhas se apresentaram comportamento menos defensivo. 
Rev. Bras. Saúde Prod. Anim., Salvador, v.16, n.4, p.925-934 out../dez.., 2015 http://www.rbspa.ufba.br ISSN 15199940

\section{REFERÊNCIAS}

BRANDEBURGO, M.A.M.; GONÇALVES, L.S. Environmental influence on the aggressive (defense) behaviour and colony development of Africanized bees (Apis mellifera).

Ciência e Cultura, v.42, n.10, p.759-771, 1990.

BREED, M.D.; GUZMAN-NOVOA, E.; HUNT, G.J. Defensive behavior of honey bees: organization, genetics, and comparisons with other bees. Annual

Review of Entomology, v.49, p.271-298, 2004.

COLLINS, A.M.; RINDERER, T.E.; TUCKER, KW. Colony defence of two honeybee types and their hybrid 1. Naturally mated queens. Journal of Apicultural Research, v.27, n.2, p.137140, 1988.

DE SOUZA, D. A.; GRAMACHO, K. P.; CASTAGNINO, G. L. B.. Produtividade de mel e comportamento defensivo como índices de melhoramento genético de abelhas africanizadas (Apis mellifera L.).

Revista Brasileira de Saúde e Produção Animal [online], v.13, n.2, p.550-557, 2012.

GONÇALVES, L.S. Comments on the aggressiveness of the Africanized bees in Brazil. American Bee Journal, v.114, n.12, p.448-450, 1974.

KAPLAN, J.K. More buzz about a bad bee; Africanized honey bees in the news again. Agricultural Research, v.54, n.2, p.4-7, 2007.

KASPEREK, K.; PALEOLOG, J.; OLSZEWSKI, K.; BORSUK, G.; STRACHECKA, A. Comparison of the defensive behaviour of Apis mellifera $\mathrm{L}$. workers and the aggression of their queen sisters. Medycyna Weterynaryjna, v.68, n.10, p.589-593, 2012.
KASTBERGER, G.; SCHMELZER, E.; KRANNER, I. Social waves in giant honeybees repel hornets. Plos One, v.3, n.9, 2008.

KERR, W.E. The history of the introduction of African bees to Brazil. South African Bee Journal, v.39, n.2, p.3-5, 1967.

MEDEIROS, F. R. F.; SILVEIRA, D. C.; LEITE, D. T.; SAMPAIO, R. B.; LUCAS, C. I. S.; SANTOS, L. O.; MARACAJÁ, P. B.; Defensividade de abelhas africanizadas associadas a diferentes temperaturas. Agropecuária Científica no Semiárido, v.9, n.4, p.107113, 2013.

MENDES, C.G.; SILVA, J.B.A.; MESQUITA, L.X.; MARACAJÁ, P.B. As análises de mel: revisão. Revista Caatinga, v.22, n.2, p.7-14, 2009.

NASCIMENTO, F.J.; GURGEL, M.; MARACAJÁ, P.B. Avaliação da agressividade de abelhas africanizadas (Apis mellifera) associada à hora do dia e a temperatura no município de Mossoró RN. Revista de Biologia e Ciências da Terra, v.5, n.2, p.12-22, 2005.

NASCIMENTO, F.J.; MARACAJÁ, P.B.; DINIZ FILHO, E.T.; MAIA, F.J.; OLIVEIRA, R.M.N. Agressividade de abelhas africanizadas (Apis mellifera) associada à hora do dia e a umidade em Mossoró-RN. Acta Veterinaria

Brasilica, v.2, n.3, p.80-84, 2008.

PAPACHRISTOFOROU, A.; RORTAIS, A.; SUEUR, J.; ARNOLD, G. Attack or retreat: contrasted defensive tactics used by Cyprian honeybee colonies under attack from hornets. Behavioural Processes, v. 86, n.2, p.236-241, 2011. 
Rev. Bras. Saúde Prod. Anim., Salvador, v.16, n.4, p.925-934 out../dez.., 2015 http://www.rbspa.ufba.br

QUEIROGA, V.P.P.; SILVEIRA, D.C.; LEITE, D.T.; SAMPAIO, R.B.; LUCAS, C.I.S.; SANTOS, L.O.; MARACAJÁ, P.B. Influência da temperatura e da alimentação na defensividade de abelhas africanizadas nas condições do semiárido paraibano.

Agropecuária Científica no

Semiárido, v.10, n.1, p.102-110, 2014.

STATISTICAL ANALYSIS SYSTEM SAS. User's Guide.Versão 9.0. Cary, North Carolina, USA: SAS Institute Inc., 2002.

\section{SHARMA, S. Applied Multivariate}

Techniques. New York: Wiley, 1995. $512 p$.

\section{SIGMAPLOT. SigmaPlot for} windows. Versão 12.0. San Jose California USA: Systat Software Inc, 2014.

SILVA, A. F.; PEREIRA, D. S.; PAIVA, C. S.; SOUZA, R. M.; MARACAJÁ, P. B.; comportamento defensivo de abelhas africanizadas na fazenda experimental-UFERSA, Mossoró-RN, Brasil. Revista Verde de Agroecologia e Desenvolvimento Sustentável - Revista Verde, v.7, n.5, p.63-72, 2012.

STABENTHEINER, A.; KOVAC, H.; SCHMARANZER, S. Honeybee nestmate recognition: the thermal behaviour of guards and their examinees. Journal of Experimental Biology, v.205, n.Pt17, p.2637-2642, 2002.

STABENTHEINER, A.; KOVAC, H.; SCHMARANZER, S. Thermal behaviour of honeybees during aggressive interactions. Ethology, v.113, n.10, p.995-1006, 2007.
STORT, A.C. Genetical study of aggressiveness of two subspecies of Apis mellifera in Brasil. Some tests measure aggressiveness. Journal of Apicultural Research, v.13, n.1, p.3338. 1974.

WARD JUNIOR, J.H. Hierarchical grouping to optimize an objective function. Journal of the American Statistical Association, v.58, n.301, p.236-244, 1967.

Data de recebimento: 04/12/2014

Data de aprovação: 06/10/2015 